British Heart fournal, 1979, 41, 697-701

\title{
Heart size and function in acromegaly
}

\author{
H. M. MATHER, M. J. BOYD, AND J. S. JENKINS \\ From the Departments of Medicine and Cardiology, St George's Hospital, London
}

SUMMARY Cardiac size and function was studied in 23 acromegalic patients using echocardiography and systolic time interval measurements. Thirteen patients $(56 \%)$ had increased left ventricular mass, and in the 20 treated patients this correlated well with the mean of the recent basal growth hormone levels. It is suggested that myocardial hypertrophy may regress in proportion to the degree of control of growth hormone levels. The ejection fraction was normal in all patients except one, and increased left ventricular mass was not associated with detectable impairment of left ventricular performance. Thus, most acromegalic hearts function normally even when their mass is considerably increased, though the longterm effects of this are unknown. Echocardiography will be valuable in the serial monitoring of the cardiac effects of acromegaly.

Cardiac enlargement has been known to be a feature of acromegaly since the end of the last century (Huchard, 1895), and an increase in overall cardiac mass, occasionally to an extreme degree, is typically found at necropsy (Courville and Mason, 1938; Hejtmancik et al., 1951). Heart failure is an uncommon but well-recognised complication, and may occur even in the absence of associated hypertension or ischaemic heart disease (Courville and Mason, 1938; Pepine and Aloia, 1970). It might be expected that the increase in cardiac mass leads to impaired performance, but there is little documented evidence to support this, nor is it established whether the myocardial hypertrophy is reversible after treatment of acromegaly. We have, therefore, studied a group of acromegalic patients, using echocardiographic recordings and systolic time interval data to estimate both left ventricular mass and performance, in order to investigate the relation between these two indices, and to consider the possible effects of treatment on left ventricular mass.

\section{Patients (see Table 1)}

Studies were made on 23 patients in whom a diagnosis of acromegaly had been made from the clinical features and demonstration of a resting, fasting growth hormone (GH) level exceeding $10 \mathrm{mU} / 1$ which was not suppressed by a $50 \mathrm{~g}$ oral glucose load. There were 12 men and 11 women, with ages

Received for publication 30 October 1978 ranging from 24 to 80 years (mean age 46 years). The estimated duration of the disease ranged from 1 to 30 years. Thirteen patients had been treated by hypophysectomy (with or without external radiotherapy), 7 patients had been treated conservatively by external radiotherapy only, and 3 patients were untreated. Nine patients were receiving hydrocortisone and thyroxine replacement therapy. Eighteen patients had normal $\mathrm{GH}$ levels at the time of the study, and in 15 of these the levels had remained within the normal range for at least 1 year. Four patients (cases 5, 8, 10, and 23) had moderate to severe hypertension (blood pressure $>160 / 110$ $\mathrm{mmHg}$ ), and 4 patients (cases 19,20,21, and 22) had mild hypertension ( $130 / 95$ to $150 / 100 \mathrm{mmHg}$ ). Case 7 had coexisting Addison's disease and had been receiving treatment with cortisol and fludrocortisone for 12 years. Case 20 had overt diabetes, and had a myocardial infarction 1 year before the study. None of the other patients had a history suggestive of ischaemic heart disease, and none had the clinical symptoms or signs of cardiac failure.

\section{Methods}

Each patient attended the outpatient clinic in a fasting state. A standard 12-lead electrocardiogram was performed and a chest radiograph was taken. Blood was taken after the patient had rested for 30 minutes, and the growth hormone concentration was measured by double antibody radioimmunoassay (Hartog and Wright, 1969), using a W.H.O. standard. 
Table 1 Clinical details of acromegalic patients

\begin{tabular}{|c|c|c|c|c|c|c|c|c|}
\hline \multirow[t]{2}{*}{ Case no. } & \multirow{2}{*}{$\begin{array}{l}\text { Age } \\
(y)\end{array}$} & \multirow[t]{2}{*}{ Sex } & \multirow{2}{*}{$\begin{array}{l}\text { Blood pressure } \\
\text { (mmHg) }\end{array}$} & \multirow{2}{*}{$\begin{array}{l}\text { Estimated } \\
\text { duration of } \\
\text { disease } \\
(y)\end{array}$} & \multirow{2}{*}{$\begin{array}{l}\text { Time since } \\
\text { treatment } \\
(y)\end{array}$} & \multicolumn{3}{|c|}{ Growth hormone concentration } \\
\hline & & & & & & Initial & $\begin{array}{l}\text { Current } \\
(m U / l)\end{array}$ & $\begin{array}{l}\text { Mean } \\
\text { recent }\end{array}$ \\
\hline 1 & 24 & $\mathrm{~F}$ & $130 / 80$ & 8 & 5 & - & $5 \cdot 2$ & 3.0 \\
\hline 2 & 24 & $\mathrm{~F}$ & $140 / 80$ & 11 & 6 & 300 & $7 \cdot 0$ & $8 \cdot 0$ \\
\hline 3 & 27 & $\mathbf{F}$ & $120 / 70$ & 2 & 1 & 20 & $4 \cdot 8$ & $5 \cdot 0$ \\
\hline 4 & 28 & $\mathrm{~F}$ & $120 / 80$ & 9 & 8 & 340 & $2 \cdot 4$ & $2 \cdot 0$ \\
\hline 5 & 48 & $\mathrm{~F}$ & $160 / 115$ & 13 & 8 & 76 & 9.0 & 13 \\
\hline 6 & 49 & $\mathrm{~F}$ & $140 / 90$ & 4 & 3 & 114 & $4 \cdot 8$ & $7 \cdot 0$ \\
\hline 7 & 53 & $\mathrm{~F}$ & $120 / 80$ & 1 & - & 176 & 176 & - \\
\hline 8 & 57 & $\mathrm{~F}$ & $220 / 110$ & 16 & 1 & 125 & 1.0 & 1.5 \\
\hline 9 & 58 & F & $140 / 90$ & 7 & 2 & 24 & $5 \cdot 6$ & 22 \\
\hline 10 & 59 & $\mathrm{~F}$ & $140 / 110$ & 9 & 6 & 11 & 1.8 & $4 \cdot 0$ \\
\hline 11 & 67 & $\mathrm{~F}$ & $135 / 90$ & 10 & 7 & 60 & $5 \cdot 5$ & $8 \cdot 0$ \\
\hline 12 & 27 & $M$ & $120 / 80$ & 10 & 6 & 26 & $1 \cdot 2$ & $1 \cdot 0$ \\
\hline 13 & 28 & $M$ & $140 / 80$ & 14 & - & 420 & 420 & - \\
\hline 14 & 36 & $M$ & $140 / 90$ & 4 & 2 & 200 & $2 \cdot 2$ & $6 \cdot 0$ \\
\hline 15 & 37 & M & $120 / 80$ & 10 & 9 & 44 & $4 \cdot 5$ & $7 \cdot 0$ \\
\hline 16 & 41 & M & $120 / 80$ & 2 & 1 & 60 & 1.9 & $2 \cdot 0$ \\
\hline 17 & 46 & $M$ & $120 / 80$ & 12 & 3 & 100 & $1 \cdot 3$ & 21 \\
\hline 18 & 49 & $\mathbf{M}$ & $120 / 85$ & 10 & 3 & 37 & $3 \cdot 1$ & $2 \cdot 0$ \\
\hline 19 & 51 & $\mathbf{M}$ & $135 / 100$ & 12 & 3 & 12 & $2 \cdot 2$ & $7 \cdot 0$ \\
\hline 20 & 55 & $\mathbf{M}$ & $130 / 95$ & 8 & 5 & 290 & 18 & 17 \\
\hline 21 & 56 & $\mathbf{M}$ & $150 / 100$ & 30 & - & 30 & 30 & - \\
\hline 22 & 57 & $M$ & $150 / 95$ & 27 & 5 & 61 & $5 \cdot 2$ & $6 \cdot 0$ \\
\hline 23 & 80 & M & $190 / 110$ & 6 & 4 & 34 & 14 & 21 \\
\hline
\end{tabular}

${ }^{\star}$ Mean recent $=$ the mean of the basal growth hormone estimations performed during the 12 months before the study (usually 3 samples).

\section{ECHOCARDIOGRAPHIC RECORDINGS}

These were made using an Ekoline 20 ultrasonoscope and a $2.25 \mathrm{MHz}$ focused transducer, the output being displayed through a Cambridge multichannel recorder together with a standard electrocardiographic lead, and recorded on photographic paper at $50 \mathrm{~mm} / \mathrm{s}$. The transducer was adjusted to obtain optimal recordings of both the interventricular septum and left ventricular posterior wall.

Analysis of the echocardiograms was carried out by one of us (M.J.B.) without knowledge of the patients' clinical and laboratory findings. The following measurements were made from the anterior edges of the appropriate echoes, taking the mean values of 5 cardiac cycles:

(1) The left ventricular internal diameter, both at end-diastole (LVD) and at end-systole (LVS).

(2) The interventricular septal thickness (ST) at end-diastole.

(3) The left posterior wall thickness (PWT) (the distance between the endocardial and epicardial echoes at end-diastole). Measurement from the anterior edges of these echoes gives a smaller normal range than that usually quoted (Feigenbaum, 1976) but is theoretically more valid (Roelandt, 1977) and has produced a range of left ventricular mass in 20 normal subjects of 80 to $200 \mathrm{~g}$ (mean $140 \mathrm{~g}$ ); this corresponds well to that of 91 to $203 \mathrm{~g}$ (mean $135 \mathrm{~g}$ ) reported from necropsy examination of normal hearts (Reiner et al., 1959).

The following calculations were made (Feigen- baum, 1976):

(1) Ejection fraction of the left ventricle (EF)

$$
=\frac{\text { LVD }^{3}-\mathrm{LVS}^{3}}{\mathrm{LVD}^{3}}
$$

(2) Left ventricular mass (LVM)

$$
=\left[(\mathrm{LVD}+\mathrm{ST}+\mathrm{PWT})^{3}-\mathrm{LVD}^{3}\right] \times 1.05
$$

(where $1.05=$ specific gravity of cardiac muscle).

\section{SYSTOLIC TIME INTERVAL MEASUREMENTS}

These were made from simultaneous recordings of high frequency phonocardiograms, carotid pulse (using a hand-held funnel pick-up, air-coupled to a crystal transducer), and the standard electrocardiographic lead which showed the earliest onset of the QRS complex, using the Cambridge recorder on photographic paper at $200 \mathrm{~mm} / \mathrm{s}$. Values for the pre-ejection period (PEP), left ventricular ejection time (LVE'T), and hence the PEP/LVET ratio were derived according to the method described by Weissler and Garrard (1971), again without knowledge of the clinical details of the patient concerned.

\section{Results (see Table 2)}

LEFT VENTRICULAR MASS (LVM)

Thirteen patients $(56 \%)$ showed increased left ventricular mass, which exceeded $300 \mathrm{~g}$ in 5 patients, and in 3 of these (cases 9, 13, and 17) was more than $400 \mathrm{~g}$. In general the left ventricular 
Table 2 Echocardiographic and systolic time interval measurements and calculations

\begin{tabular}{|c|c|c|c|c|c|}
\hline Case no. & $\begin{array}{l}\text { Posterior wall thickness } \\
(\mathrm{cm})\end{array}$ & $\begin{array}{l}\text { Interventricular septal } \\
\text { thickness } \\
(\mathrm{cm})\end{array}$ & $\begin{array}{l}\text { Left ventricular mass } \\
(g)\end{array}$ & Ejection fraction & PEP $/ L V E T$ ratio \\
\hline $\begin{array}{r}1 \\
2 \\
3 \\
4 \\
5 \\
6 \\
7 \\
8 \\
9 \\
9 \\
10 \\
11 \\
12 \\
13 \\
14 \\
15 \\
16 \\
17 \\
18 \\
19 \\
20 \\
21 \\
22 \\
23\end{array}$ & $\begin{array}{l}0.8 \\
0.9 \\
0.85 \\
0.8 \\
1.2 \\
1.0 \\
0.6 \\
1.0 \\
1.5 \\
0.8 \\
0.85 \\
1.0 \\
1.5 \\
1.0 \\
0.7 \\
0.75 \\
1.2 \\
1.0 \\
0.85 \\
0.95 \\
0.9 \\
1.05 \\
1.05\end{array}$ & $\begin{array}{l}1.0 \\
0.9 \\
0.8 \\
0.75 \\
1.3 \\
1.25 \\
0.50 \\
0.95 \\
2.0 \\
1.5 \\
0.9 \\
0.7 \\
1.4 \\
0.95 \\
0.8 \\
0.7 \\
1.6 \\
1.2 \\
0.9 \\
1.7 \\
0.8 \\
1.3 \\
1.0\end{array}$ & $\begin{array}{l}249 \\
227 \\
134 \\
173 \\
221 \\
288 \\
158 \\
138 \\
583 \\
246 \\
173 \\
134 \\
788 \\
277 \\
189 \\
116 \\
489 \\
213 \\
174 \\
321 \\
136 \\
272 \\
372\end{array}$ & 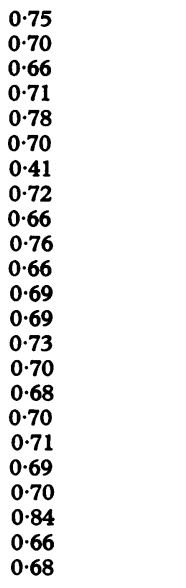 & $\begin{array}{l}0.31 \\
0.38 \\
0.41 \\
0.41 \\
0.39 \\
0.41 \\
0.80 \\
0.33 \\
0.38 \\
0.31 \\
0.35 \\
0.38 \\
0.41 \\
0.37 \\
0.37 \\
0.42 \\
0.33 \\
0.42 \\
0.39 \\
0.63 \\
0.39 \\
0.52 \\
0.53\end{array}$ \\
\hline $\begin{array}{l}\text { Normal s } \\
\text { Mean } \\
\text { SD } \\
\text { Range }\end{array}$ & $\begin{array}{l}\text { bjects } \\
0.7^{\star} \\
0.1 \\
0.5-0.9\end{array}$ & $\begin{array}{l}0 \cdot 8^{\star} \\
0 \cdot 1 \\
0 \cdot 6-1 \cdot 0\end{array}$ & $\begin{array}{l}140^{\star} \\
30 \\
80-200\end{array}$ & $\begin{array}{l}0.75^{\star} \\
0.07 \\
0.61-0.89\end{array}$ & $\begin{array}{l}+0.35 \\
0.04 \\
\\
0.27-0.43\end{array}$ \\
\hline
\end{tabular}

*Values obtained from 20 normal subjects (10 men and 10 women) aged 24 to 54 years (mean 39 years).

Normal values published by Weissler and Garrard (1971).

hypertrophy was concentric in nature, but in 4 patients (cases $9,10,17$, and 20 ) the interventricular septum was disproportionately thick.

\section{EJECTION FRACTION}

This was within normal limits in all patients except one (case 7).

\section{SYSTOLIC TIME INTERVAL MEASUREMENTS}

The PEP/LVET ratio was abnormally high in 4 patients (cases $7,20,22$, and 23).

\section{ELECTROCARDIOGRAMS}

These were within normal limits, except in case 20 who had evidence of a previous myocardial infarction, and cases 19 and 23 who had abnormally flattened $\mathrm{T}$ waves in leads $\mathrm{I}$, aVL, and V4-6.

\section{RADIOGRAPHS OF CHEST}

The cardiothoracic ratio exceeded 0.5 in 2 patients (cases 5 and 9), but in general the correlation between heart size shown radiologically and that measured by echocardiography was poor.

\section{Discussion}

Myocardial hypertrophy, indicated by an increased left ventricular mass, was present in $13(56 \%)$ out of 23 patients with acromegaly of widely varying severity. There was no correlation between increase in left ventricular mass and either the estimated duration of the disease or the $\mathrm{GH}$ levels before treatment. Similarly, there was no correlation between increase in left ventricular mass and the presence or severity of hypertension; indeed the 3 patients with the greatest left ventricular mass (cases 9, 13, and 17) were normotensive.

However, the persistence of high GH levels after treatment appeared to be important. Thus, we found a close relation between the left ventricular mass and the mean value of the basal GH levels during the year before the study in the 20 treated patients (Fig.). The left ventricular mass was normal or only moderately raised in the 15 patients whose GH levels had been well controlled for at least 1 year, whereas it was clearly greater in 4 of the 5 patients in whom the treatment had been unsuccessful, or in whom reduction of GH levels was very recent; only 1 of these 4 patients had associated hypertension. Though echocardiography was not performed before treatment, this relation suggests that the myocardial hypertrophy of acromegaly may regress after treatment in proportion to the degree of control of GH levels. However, serial studies on these patients are needed to confirm this.

One of the 3 untreated patients (case 13) had very 


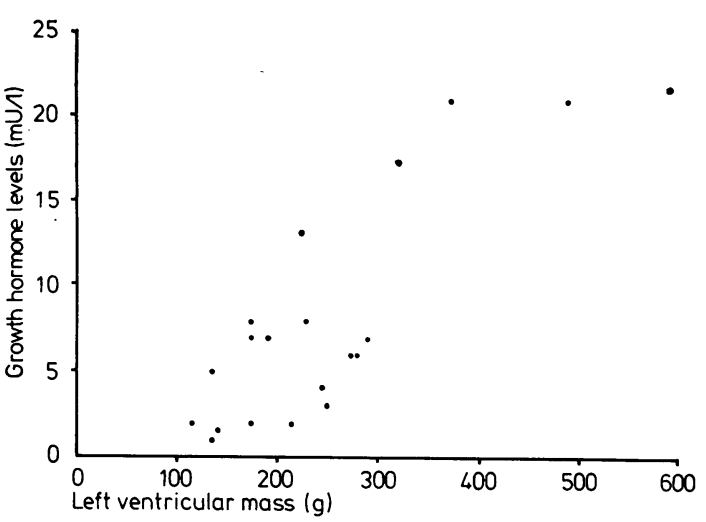

Fig. The relation between left ventricular mass and mean recent growth hormone levels in treated acromegalic patients.

high GH levels and a correspondingly high left ventricular mass, but in the other 2 untreated patients (cases 7 and 21) the left ventricular mass was normal, despite raised GH levels. However, in case 7 the acromegaly was of recent onset, and moreover this patient also had Addison's disease. The other patient (case 21) was unusual in that the clinical appearances of acromegaly had remained unchanged for many years.

Our finding that the majority of the patients with hypertrophy manifested a concentric increase in wall thickness and that only a small number of patients appeared to have a disproportionately thick septum accords with the experience of others (Bodem et al., 1976; Savage et al., 1976). The suggestion in a recent report (Hearne et al., 1975) that this latter feature occurs in almost all acromegalics, and is thus a diagnostic feature, was not substantiated; indeed it is now recognised that a minority of patients with left ventricular hypertrophy from any cause (such as aortic stenosis) may have disproportionate septal thickening (Maron et al., 1977) and it appears that acromegalic hearts show the same general pattern.

The use of the left ventricular ejection fraction to evaluate myocardial performance is well established, and a good correlation exists between the values of ejection fraction derived from echocardiographic measurements and those obtained by angiography (Feigenbaum et al., 1972; Murray et al., 1972), provided that there is no segmental wall motion abnormality (Feigenbaum, 1976). The ratio of pre-ejection period (PEP) to left ventricular ejection time (LVET) has been shown to be increased in subjects with heart failure (Weissler et al., 1968) and has also been used as an index of left ventricular performance. Only 1 patient (case 7) in our series of 23 acromegalic subjects was found to have an abnormally small ejection fraction, and this patient also had the highest PEP/LVET ratio; she was atypical in that her acromegaly was superimposed on long-standing Addison's disease but, since she had been receiving apparently adequate adrenocortical hormone replacement therapy for many years, the contribution of this additional factor was difficult to assess. In the other 22 patients the ejection fraction was normal. Three of these other patients had an abnormally high PEP/LVET ratio (in each case resulting from a prolonged preejection period) but in 2 this can be attributed to other factors, namely the previous myocardial infarction of case 20 (Weissler and Garrard, 1971), and the advanced age of case 23 (Harrison et al., 1964). The explanation in case 22 is obscure, but the reliability of systolic time interval criteria in the individual subject has been questioned since falsely positive and negative values are not uncommon (Braunwald et al., 1976), and there is now considerable evidence favouring ejection fraction as the best overall index of basal left ventricular function (Braunwald et al., 1976). Thus we found convincing evidence of subclinical impairment of myocardial performance in only 1 patient (case 7); further, there was no correlation between the left ventricular mass and either the ejection fraction or the PEP/LVET ratio.

It does not, therefore, seem that increasing myocardial hypertrophy leads to impaired function, and indeed most acromegalic hearts appear to function well, regardless of size. This is in agreement with other reports (Bodem et al., 1976; Martins et al., 1977). Our study does not support the findings of a report on 10 acromegalic patients, in which a high incidence of subclinical muscle disease was suggested on the basis of systolic time interval measurements alone (Jonas et al., 1975). However, the PEP/ LVET ratio was strikingly abnormal in only 2 patients in the above report, 1 of whom had previously had a myocardial infarction; in the other patients the abnormal ratios were largely the result of a shortened left ventricular ejection time with a normal pre-ejection period, which is not the pattern that theoretical considerations would predict in subclinical myocardial disease. The low incidence of subclinical myocardial impairment in our acromegalic patients contrasts with the high prevalence of overt cardiac failure described in earlier reports (Courville and Mason, 1938; Hejtmancik et al., 1951). It is possible that this represents a true fall in the incidence of myocardial dysfunction, related in part to earlier and more effective definitive treatment.

In conclusion, we found that considerable myo- 
cardial hypertrophy in treated patients was only present when control of growth hormone levels was inadequate, suggesting that the former may be at least partially reversible after effective treatment. There was no evident correlation between myocardial hypertrophy and performance, and indeed the latter was normal in all patients except one. Nevertheless, the long-term functional effects of the hypertrophy, persisting over decades, remain unclear. The serial use of echocardiography in individual patients promises to be of importance in assessing the effect of treatment in preventing potentially serious alterations of heart size and function in acromegaly.

We thank Dr Aubrey Leatham and Mr G. Leech for helpful advice and criticism and $\mathrm{Mr} \mathrm{V}$. Ang for performing the growth hormone estimations. M.J.B. was supported by a grant from St George's Hospital Medical Research Committee.

\section{References}

Braunwald, E., Ross, J., and Sonnenblick, E. H. (1976). Mechanisms of Contraction of the Normal and Failing Heart, 2nd edn. Little, Brown, Boston.

Bodem, R., Albig, M., Barwich, D., and Sonnenblick, E. H. (1976). The heart in acromegaly: echocardiographic findings (abstract). Circulation, 53 and 54, Suppl. II, 79.

Courville, C. B., and Mason, V. R. (1938). The heart in acromegaly. Archives of Internal Medicine, 61, 704-713.

Feigenbaum, H. (1976). Echocardiography, 2nd edn. Lea and Febiger, Philadelphia.

Feigenbaum, H., Popp, R. L., Wolfe, S. B., Troy, B. L., Pombo, J. F., Haine, C. L., and Dodge, H. T. (1972). Ultrasound measurements of the left ventricle: a correlative study with angiography. Archives of Internal Medicine, 129, 461-467.

Harrison, T. R., Dixon, K., Russel, R. O., jun, Bidwai, P. S., and Coleman, H. N. (1964). Relation of age to the duration of contraction, ejection and relaxation of the normal human heart. American Heart Fournal, 67, 189-199.

Hartog, M., and Wright, A. D. (1969). The radioimmuno- assay of growth hormone. British fournal of Hospital Medicine, 2, 853-858.

Hearne, M. J., Sherber, H. S., and deLeon, A. C. (1975). Asymmetric septal hypertrophy in acromegaly-an echocardiographic study (abstract). Circulation, 51 and 52, Suppl. II, 35.

Hejtmancik, M. R., Bradfield, J. Y., jun, and Hermann, G. R. (1951). Acromegaly and the heart: a clinical and pathologic study. Annals of Internal Medicine, 34, 1445-1456.

Huchard, H. (1895). Anatomic pathologique, lésions et troubles cardio-vasculaires de l'acromégalie. Fournal des Praticiens, 9, 249.

Jonas, E. A., Aloia, J. F., and Lane, F. J. (1975). Evidence of subclinical heart muscle dysfunction in acromegaly. Chest, 67, 190-194.

Maron, B. J., Clark, C. E., Henry, W. L., Fukuda, T., Edwards, J. E., Matthews, E. C., jun, Redwood, D. R., and Epstein, S. E. (1977). Prevalence and characteristics of disproportionate ventricular septal thickening in patients with acquired or congenital heart diseases. Circulation, 55, 489-496.

Martins, J. B., Kerber, R. E., Sherman, B. M., Marcus, M. L., and Ehrhardt, J. C. (1977). Cardiac size and function in acromegaly. Circulation, 56, 863-869.

Murray, J. A., Johnston, W., and Reid, J. M. (1972). Echocardiographic determination of left ventricular dimensions, volumes and performance. American fournal of Cardiology, 30, 252-257.

Pepine, C. J., and Aloia, J. (1970). Heart muscle disease in acromegaly. American fournal of Medicine, 48, 530-534.

Reiner, L., Mazzoleni, A., Rodriguez, F. L., and Frendenthal, R. R. (1959). The weight of the human heart. I. Normal cases. Archives of Pathology, 68, 58-73.

Roelandt, J. (1977). Practical Echocardiology. Research Studies Press, Forest Grove, Oregon.

Savage, D. D., Eastman, R. C., Henry, W. L., Borer, J. S., Ross, J., and Gordon, P. (1976). Echocardiographic evaluation of acromegalic patients (abstract). Circulation, $\mathbf{5 3}$ and 54, Suppl. II, 22.

Weissler, A. M., and Garrard, C. L. (1971). Systolic time intervals in cardiac disease. Modern Concepts of Cardiovascular Disease, 40, 1-8.

Weissler, A. M., Harris, W. S., and Schoenfeld, C. D. (1968). Systolic time intervals in heart failure in man. Circulation, 37, 149-159.

Requests for reprints to Professor J. S. Jenkins, St George's Hospital Medical School, Cranmer Terrace, London SW 17 ORE. 